\title{
Driver oncogenes in Sub-Saharan African patients with non-small cell lung cancer
}

This article was published in the following Dove Press journal:

Lung Cancer:Targets and Therapy

30 November 2016

Number of times this article has been viewed

\author{
Barbara Legius' \\ Sandra Van Den Broecke' \\ Inge Muylle' \\ Vincent Ninane ${ }^{1,2}$ \\ 'Department of Pulmonology, Centre \\ Hospitalier Universitaire Saint Pierre, \\ ${ }^{2}$ Faculty of Medicine, Université Libre \\ de Bruxelles, Brussels, Belgium
}

\begin{abstract}
Non-small cell lung cancer can exhibit driver oncogenes, including epidermal growth factor receptor (EGFR) and anaplastic lymphoma kinase (ALK), that are possible targets for therapy. The prevalence of these rearranged driver oncogenes is influenced by race, smoking habits, and gender. Most data come from Caucasian and Asian populations. To our knowledge, there is no literature available about the prevalence of driver oncogenes in Sub-Saharan Africa, where the tobacco epidemic is still in the early stage. In this small case series, 6 patients of Sub-Saharan African ethnicity with stage IV lung adenocarcinoma are described. EGFR mutation was present in $3 / 6$ patients and ALK rearrangement in $1 / 6$ patients. This incidence seems high but interestingly, all patients were non-smokers or light smokers. In this series, the high prevalence of driver oncogene was probably related to low smoking habits and these initial data in Sub-Saharan Africans suggest high prevalence of driver mutations for this reason.
\end{abstract}

Keywords: epidermal growth factor receptor (EGFR) mutation, anaplastic lymphoma kinase (ALK) translocation, Africa, lung adenocarcinoma

\section{Introduction}

Non-small cell lung cancer (NSCLC) can exhibit rearranged driver oncogenes, which are possible targets for therapy. ${ }^{1}$ The most frequently identified driver oncogenes in NSCLC leading to targeted therapy are epidermal growth factor receptor (EGFR) and anaplastic lymphoma kinase (ALK). ${ }^{1,2}$ The prevalence of these driver oncogenes is significantly influenced by race, smoking habits, and gender. ${ }^{3}$ The frequency of EGFRmutated NSCLC in Asian patients is known to be higher than in Caucasian patients. ${ }^{3}$ In contrast, prevalence of ALK rearrangements in NSCLC is reported to be similar in Caucasian and Asian patients. ${ }^{3}$ In recent cohort studies with Afro-Americans, there is no significant difference in the prevalence of EGFR mutations or ALK rearrangements with Caucasian Americans. ${ }^{4,5}$

About other races, however, less or no data are available. ${ }^{6,7}$ For obvious reasons, little is known about Africa. Cancer, however, is a significant health problem in this continent, as it is estimated that there were 715,000 new cancer cases in 2008, and additional data from Southern Africa and Northern Africa already confirm that lung cancer is the leading cause of death related to cancer. ${ }^{8}$ To our knowledge, there is no literature available about the prevalence of lung cancer and rearranged driver oncogenes in Sub-Saharan Africans. As the latter is influenced by race and smoking habits that may differ from Afro-Americans; we have studied the prevalence of EGFR mutations and ALK translocations in a case series of patients of Sub-Saharan African ethnicity with NSCLC.
Correspondence: Barbara Legius Centre Hospitalier Universitaire Saint Pierre, Rue Haute 322, Brussels 1000, Belgium

Tel +32 25354244

Fax +3225354I74

Email b.legius@gmail.com
Lung Cancer:Targets and Therapy 2016:7 |49-152 


\section{Materials and methods}

We retrospectively studied all patients of Sub Saharan African ethnicity who have been treated for NSCLC stage IV in our hospital (University Hospital Saint Pierre) in Brussels, Belgium. The ethics committee of Saint-Pierre Hospital deemed ethical approval not necessary as it was a retrospective study. Besides collecting data from the patient file, there was no other intervention. All patients provided written informed consent. Information was extracted from the electronic patient file (Bdoc ${ }^{\circ}$, Ciges Inc. Charleroi, Belgium). Investigations were performed on biopsies obtained during flexible bronchoscopy and these samplings were immediately fixed in neutral buffered formalin and embedded in paraffin. ${ }^{9}$ Driver oncogenes on biopsy specimens were researched by using the Truseq Amplicon Cancer Panel (Illumina ${ }^{\circ}$, Illumina Inc., San Diego, CA, USA). Not only were EGFR/ALK mutations investigated, but also other mutations included in the panel, such as tumor protein p53 (TP53), proto-oncogene B-Raf (BRAF) and Kirsten rat sarcoma viral oncogene homolog (KRAS).

\section{Results}

From July 2012 to November 2015, 6 patients of Sub-Saharan origin with NSCLC stage IV have been treated in our hospital. Their characteristics are given in Table 1. Three patients originated from Congo, an ex-Belgian colony, 1 from Djibouti, 1 from Cameroon, and 1 from Guinea. EGFR mutation was present in 3/6 patients and ALK rearrangement was present in $1 / 6$ patients. Two EGFR mutations were common, i.e., L858R (exon 21 point mutation) and deletion exon $19 .{ }^{10}$ The significance of the third EGFR mutation (T710I in exon 18) is unknown. All EGFR mutations and ALK rearrangement were present in non-smokers. Both patients without EGFR mutation and ALK rearrangement were considered as light smokers ( $<10$ pack-years). One of the 6 patients was female, she had an EGFR mutation.

\section{Discussion}

In our small case series, 4 out of 6 Sub-Saharan patients with NSCLC had a driver oncogene, either EGFR mutation or ALK rearrangement. The prevalence of rearranged driver oncogenes in NSCLC is known to be influenced by race, gender, and smoking status. ${ }^{3}$ Differences in prevalence of EGFR mutation status in NSCLC between Asian and Caucasian patients have already been extensively studied since the early 2000s. ${ }^{2,3}$ EGFR mutations (exons 18-22) are present in $\sim 30 \%$ East Asian patients with lung cancer, and more specifically in $35 \%-47 \%$ of East Asian patients with lung adenocarcinoma, whereas EGFR mutations are present in $\sim 7 \%$ of Caucasian patients with lung cancer, and in $13 \%-18 \%$ of Caucasian patients with lung adenocarcinoma. ${ }^{3,4}$ Even within the Asian population, EGFR mutation status in NSCLC varies. ${ }^{6}$ The East Asian population is the largest Asian group studied (Japanese, Korean, and Chinese patients). ${ }^{3,46}$ In a large cohort of 907 Indian patients, an EGFR mutation was found in $23 \%$ of patients with NSCLC and in $26 \%$ of lung adenocarcinomas. ${ }^{6}$

Recently, EGFR mutations in NSCLC in Afro-American patients have been investigated. ${ }^{4,511}$ There seems to be no difference in prevalence of EGFR mutations in NCSLC between Caucasians and Afro-Americans. Yamaguchi et al described a prevalence of EGFR mutations in NSCLC of $18.4 \%$ in White patients and in $18.2 \%$ of Black patients in their patient cohort. ${ }^{4}$ Bollig-Fischer et al found a prevalence of $8 \%$ of EGFR mutations in both Black and White patients with NSCLC. ${ }^{11}$ It is not clear whether these results for Afro-American patients can be extrapolated to Sub-Saharan African patients with NSCLC.

Errihani et al performed the only study, to our knowledge, on the prevalence of EGFR mutation status in lung cancer patients in the African continent. ${ }^{7}$ They examined in a Moroccan patient cohort the prevalence of EGFR muta-

Table I Patient characteristics and mutation status of NSCLC

\begin{tabular}{|c|c|c|c|c|c|c|}
\hline Patient & Sex & Age (years) & Country of origin & Staging NSCLC & Mutation status & Smoking status \\
\hline I & Female & 43 & Congo & $\begin{array}{l}\text { Stage IV } \\
\text { adenocarcinoma }\end{array}$ & $\begin{array}{l}\text { EGFR mutation } \\
\text { (L858R) }\end{array}$ & Non-smoker \\
\hline 2 & Male & 51 & Djibouti & $\begin{array}{l}\text { Stage IV } \\
\text { adenocarcinoma }\end{array}$ & ALK translocation & Non-smoker \\
\hline 3 & Male & 64 & Congo & $\begin{array}{l}\text { Stage IV } \\
\text { adenocarcinoma }\end{array}$ & $\begin{array}{l}\text { EGFR mutation (deletion } \\
\text { exon 19) }\end{array}$ & Non-smoker \\
\hline 4 & Male & 75 & Congo & $\begin{array}{l}\text { Stage IV } \\
\text { adenocarcinoma }\end{array}$ & None & $\begin{array}{l}\text { Ex-smoker } \\
(10 \mathrm{PY})\end{array}$ \\
\hline 5 & Male & 55 & Guinea & $\begin{array}{l}\text { Stage IV } \\
\text { adenocarcinoma }\end{array}$ & $\begin{array}{l}\text { EGFR mutation (T7I0I: } \\
\text { unknown significance) }\end{array}$ & Non-smoker \\
\hline 6 & Male & 74 & Cameroon & $\begin{array}{l}\text { Stage IV } \\
\text { adenocarcinoma }\end{array}$ & None & $\begin{array}{l}\text { Ex-smoker } \\
(10 \mathrm{PY})\end{array}$ \\
\hline
\end{tabular}

Abbreviations: ALK, anaplastic lymphoma kinase; EGFR, epidermal growth factor receptor; NSCLC, non-small cell lung cancer; PY, pack years. 
tions in advanced lung adenocarcinoma. A prevalence of 21\% EGFR mutations in lung adenocarcinoma was found ( 29 out of 137 patients), which lies between the prevalence of EGFR mutations in Caucasian and Asian patients with NSCLC. ${ }^{7}$ It is unclear whether the results of the Moroccan (North African) cohort also apply to Sub Saharan African patients with NSCLC.

Besides race, the presence of driver oncogenes is influenced by gender and smoking history. ${ }^{3}$ In this limited series, the role of gender was impossible to assess.

Finally, smoking status independently influences EGFR mutation status in NSCLC. ${ }^{2,3,4}$ The prevalence is higher in never smokers or light smokers. In our study, 3 out of 6 patients had an EGFR mutation. This incidence seems high, but interestingly, all our 6 patients were non-smokers or light smokers. In Europe, the prevalence of tobacco use among adults is approximately $19 \%$ for women and $38 \%$ for men. ${ }^{12}$ In the African continent, at first sight, smoking prevalence does not seem to be different, as among males it ranges from $14 \%$ in Swaziland to $40 \%$ in Niger. ${ }^{13}$ However, according to a recent analysis of the American Cancer Society, most African countries remain in the early stages of the tobacco epidemic, with tobacco use relatively low compared to the rest of the world. ${ }^{14}$ On this basis, it is likely that the proportion of lung adenocarcinoma in non-smokers is still high and this may contribute to explaining the frequent EGFR mutations in our case series. Indeed, EGFR mutations in NSCLC have been found in $35 \%-40 \%$ of Caucasian never smokers, and in $55 \%-70 \%$ of Asian never smokers. ${ }^{3,4} \mathrm{We}$ believe this explanation also applies for the finding of one ALK translocation in our small series. The overall prevalence of ALK translocation in NSCLC is thought to be $3 \%-5 \%$, without ethnic difference, but with a higher prevalence in non-smokers. ${ }^{3,4}$

Even if these results cannot be extrapolated due to the small number of patients, the early stages of the tobacco epidemic in Africa are probably associated with a high frequency of EGFR mutation and ALK rearrangement in NSCLC. This will probably change with time, as Africa is becoming a future epicenter of tobacco epidemic. ${ }^{13}$

\section{Conclusion}

In this small series, $4 / 6$ patients of Sub-Saharan origin with NSCLC presented driver oncogene rearrangements. All the
6 patients were non-smokers or light smokers. This may be related to the fact that Africa is still in the early stages of the tobacco epidemic, leading to suggest that the prevalence of driver oncogenes is high in this population. As the burden of lung cancer in Sub-Saharan countries is expected to rise in the next decennia, ${ }^{8}$ further investigations of NSCLC subgroups in this racial group are required.

\section{Disclosure}

The authors report no conflicts of interest in this work.

\section{References}

1. Pao W, Girard N. New driver mutation in non-small-cell lung cancer. Lancet Oncol. 2011;12(2):175-180.

2. Kosaka T, Yatabe Y, Endoh H, Kuwano H, Takahashi T, Mitsudomi T. Mutations of the epidermal growth factor receptor gene in lung cancer: biological and clinical implications. Cancer Res. 2004;64(24): 8919-8923.

3. Zhou W, Christiani DC. East meets West: ethnic differences in epidemiology and clinical behaviors of lung cancer between East Asians and Caucasians. Chin J Cancer. 2011;30(5):287-292.

4. Yamaguchi N, Vander Laan PA, Folch E, et al. Smoking status and self-reported race affect the frequency of clinically-relevant oncogenic alterations in non-small-cell lung cancers at a United States-based academic medical practice. Lung Cancer. 2013;82(1):31-37.

5. Clifford BT, Fu P, Pennell NA, Halmos B, Leidner RS. EGFR molecular testing in African-American non-small cell lung cancer patients - a review of discrepant data. Transl Lung Cancer Res. 2013;2(3): 251-255.

6. Chougule A, Prabhash K, Noronha V, et al. Frequency of EGFR mutations in 907 lung adenocarcinoma patients of Indian ethnicity. PLoS One. 2013;8(10):e76164.

7. Errihani H, Inrhaoun H, Boukir A, et al. Frequency and type of epidermal growth factor receptor mutations in Moroccan patients with lung adenocarcinoma. J Thorac Oncol. 2013;8(9):1212-1214.

8. Jemal A, Bray F, Forman D, O’Brien M, Ferlay J, Center M, Parkin DM. Cancer burden in Africa and opportunities for prevention. Cancer 2012;118(18):4372-4384.

9. Thunissen E, Kerr KM, Herth FJ, et al. The challenge of NSCLC diagnosis and predictive analysis on small samples. Practical approach of a working group. Lung Cancer 2012;76(1):1-18.

10. Karachaliou N, Molina-Vila MA, Rosell R. The impact of rare EGFR mutations on the treatment response of patients with non small cell lung cancer. Expert Rev Respir Med. 2015;9(3);241-244.

11. Bollig-Fischer A, Chen W, Gadgeel SM, Wenzlaff AS, Cote ML, Schwartz AG, Bepler G. Racial diversity of actionable mutations in non-small cell lung cancer. J Thorac Oncol. 2015;10(2):250-255.

12. World Health Organization. Who is smoking? Available from: http:// www.euro.who.int/en/health-topics/disease-prevention/tobacco/dataand-statistics. Accessed June 14, 2016.

13. Winkler V, Ott JJ, Cowan M, Becher H. Smoking prevalence and its impacts on lung cancer mortality in Sub Saharan Africa: an epidemiological study. Prev Med.2013;57:634-640.

14. Blecher E, Ross H. Tobacco use in Africa: tobacco control through prevention. American Cancer Society 2013. Available from: http:// www.cancer.org/acs/groups/content/@internationalaffairs/documents/ document/acspc-041584.pdf. Accessed October 16, 2016. 


\section{Publish your work in this journal}

Lung Cancer: Targets and Therapy is an international, peer-reviewed, open access journal focusing on lung cancer research, identification of therapeutic targets and the optimal use of preventative and integrated treatment interventions to achieve improved outcomes, enhanced survival and quality of life for the cancer patient. Specific topics covered in the journal include: Epidemiology, detection and screening; Cellular research and biomarkers; Identification of biotargets and agents with novel published authors.

mechanisms of action; Optimal clinical use of existing anticancer agents, including combination therapies; Radiation and surgery; Palliative care; Patient adherence, quality of life, satisfaction; Health economic evaluations. The manuscript management system is completely online and includes a very quick and fair peer-review system. Visit http://www.dovepress.com/testimonials.php to read real quotes from

Submit your manuscript here: https://www.dovepress.com/lung-cancer-targets--therapy-journal 